\title{
FREE RADICAL SCAVENGING, ANTIOXIDANT POTENTIAL, AND NITRIC OXIDE INHIBITION IN HUMAN THP1 DERIVED MACROPHAGES BY KOKILAKSHAM KASHAYAM
}

\author{
TEENA MERLIN ${ }^{1}$, PRAKASH KUMAR B ${ }^{2 *}$
}

${ }^{1}$ Inflammation Research Lab, School of Biosciences, Mahatma Gandhi University, Kottayam, Kerala, India. ${ }^{2}$ School of Biosciences, Mahatma Gandhi University, Kottayam, Kerala, India. Email: prakashkumar@mgu.ac.in

Received: 04 May 2019, Revised and Accepted: 12 June 2019

\section{ABSTRACT}

Objective: The aim of this study was to evaluate the antioxidant potential of Kokilaksham kashayam and its effect on the production of nitric oxide (NO) by lipopolysaccharide (LPS) stimulated THP1 derived macrophages.

Methods: Kokilaksham kashayam was subjected to fractionation and assessed for antioxidant activity. The effect of fractions on cell viability was determined using 3-(4,5 - dimethylthiazol -2-yl)-2,5-diphenyltetrazolium bromide assay and the fractions were evaluated for their effect on the production of NO by LPS stimulated THP1 derived macrophages.

Results: It was found that the fractions of the herbal decoction were able to scavenge a variety of free radicals 2,2-diphenyl-1-picrylhydrazyl, 2,2'-azino-bis(3-ethylbenzothiazoline-6-sulfonic acid, and NO. Ferric reducing antioxidant power assay showed the antioxidant capacity and cell culture studies in THP derived macrophages showed that the fractions inhibited the production of NO in LPS-stimulated THP1 derived macrophages.

Conclusion: The overall study showed that the proinflammatory role of free radicals in general and specifically NO in chronic inflammatory condition could be managed by the use of Kokilaksham kashayam. The inhibitory effect of Kokilaksham kashayam on NO production and free-radical scavenging activity, in general, proves that the vital phytoconstituents in the herbal decoction are responsible for the antioxidant activity thereby preventing or slowing the process of chronic inflammatory conditions.

Keywords: Kokilaksham kashayam, Free radicalscavenging assays, THP1 derived macrophages, Nitric oxide.

(C) 2019 The Authors. Published by Innovare Academic Sciences Pvt Ltd. This is an open access article under the CC BY license (http://creativecommons. org/licenses/by/4. 0/) DOI: http://dx.doi.org/10.22159/ajpcr.2019.v12i8.33932

\section{INTRODUCTION}

Inflammation is the vital response of the immune system, which enables the maintenance of the normal tissue homeostasis during infection and tissue injury [1]. During the body's normal metabolism, a large number of free radicals are generated [2]. There is an elaborate mechanism by the biological framework for removal of the generated free radicals which are not necessarily a threat under normal physiological condition. However, reactive oxygen species (ROS) and other free radicals when generated excessively, damage the molecules in cell and tissues leading to an adverse effect on the body. Oxidative stress can be defined as an imbalance between the oxidative forces and the antioxidant defense system of the human body [3]. To withstand such a situation, nature has gifted humankind with an immense number of antioxidant sources. Ayurvedic formulation serves as a goldmine comprising a large mixture of phytochemicals obtained from the natural wealth "plants," which are useful for the treatment of pathological conditions. This study evaluates the antioxidant property of Kokilaksham kashayam and its effect on the production of nitric oxide (NO) from THP1 derived macrophages.

\section{METHODS}

Kokilaksham kashayam prepared as per the classical Ayurveda text Ashtanga Hridayam Chikitsa Sthana was procured from Arya Vaidya Sala Kottakkal. Each $10 \mathrm{ml}$ of the decoction contains $18.520 \mathrm{~g}$ Hygrophila schulli M.R. Almeida and S.M. Almeida. 2,2'-azino-bis(3ethylbenzothiazoline-6-sulfonic acid (ABTS), sodium nitroprusside, 2,4,6-Tri(2-pyridyl)-s-triazine (TPTZ), phenazine methosulfate nicotinamide adenine dinucleotide, nitro blue tetrazolium, dimethyl sulfoxide (DMSO), dibutylhydroxytoluene (BHT), quercetin, indomethacin, and 3-(4,5 - dimethylthiazol -2-yl)-2,5diphenyltetrazolium bromide (MTT) were purchased from HiMedia Ltd., India. 2,2-diphenyl-1-picrylhydrazyl (DPPH), Phorbol 12-Myristate 13-Acetate (PMA), and lipopolysaccharide (LPS)-Escherichia coli 0111 were purchased from Sigma Chemical Co., USA. Solvent like hexane, dichloromethane, ethyl acetate, methanol were purchased from Merck, India and ultrapure water was obtained from Elga water purifier(Italy). Human leukemia cell line THP1 was procured from National Centre for Cell Science, Pune and cultured in RPMI-1640 culture medium supplemented with $10 \%$ heat-inactivated fetal bovine serum, $4.5 \mathrm{~g}$ glucose, $100 \mathrm{U} / \mathrm{ml}$ of penicillin, and $0.1 \mathrm{mg} / \mathrm{ml}$ of streptomycin (HiMedia Ltd. India) and incubated in a $\mathrm{CO}_{2}$ incubator at $37^{\circ} \mathrm{C}$ at $5 \% \mathrm{CO}_{2}$.

\section{Fractionation of herbal decoction}

Kokilaksham kashayam was fractionated successively with five solvents of increasing polarity (hexane, dichloromethane, ethyl acetate, methanol, and water). The fractions labeled F1, F2, F3, F4, and F5, respectively, were collected, evaporated using rotary evaporator, lyophilized, and stored at $4^{\circ} \mathrm{C}-$ until further analysis.

Qualitative analysis of phytochemical constituent The preliminary qualitative phytochemical analysis of the fractions was performed as per the standard procedures $[4,5]$.

\section{Quantitative analysis of phytochemical constituents} Estimation of total phenol content

The total phenol content in the fractions was determined according to Folin-Ciocalteu reagent assay [6]. The content of total phenol was expressed in terms of gallic acid equivalent. 
Estimation of flavonoid

The total flavonoid content in the fractions was determined according to the aluminum chloride colorimetric method described by Kumar et al. [7]. The content of flavonoid was determined using quercetin as a reference compound.

\section{Estimation of phenolic acid}

The amount of phenolic acid in the fractions was estimated by a colorimetric method in which the pink color develops on reaction with Arnov's reagent [8]. The amount of phenolic acid was determined using caffeic acid as standard.

\section{Antioxidant assays}

DPPH assay

DPPH assay was done as per the protocol of Floegel et al. [9]. To 100 $\mu \mathrm{l}$ of the sample at different concentration $(6.25 \mu \mathrm{g}-100 \mu \mathrm{g} / \mathrm{ml}), 100$ $\mu \mathrm{l}$ of DPPH reagent was added. The mixture was shaken vigorously, incubated in the dark for $30 \mathrm{~min}$ and the absorbance was read at $520 \mathrm{~nm}$ in Thermo Scientific Varioskan ELISA plate reader. $100 \mu \mathrm{l}$ of methanol along with $100 \mu \mathrm{l}$ of DPPH reagent served as the control and BHT was used as the standard for the experiment. The percentage of DPPH scavenging of the samples was calculated as per the following equation. Percent DPPH scavenging $=(\mathrm{AC}-\mathrm{AT}) / \mathrm{BHT}^{*} 100$, where $\mathrm{AC}$ is the absorbance of the control and AT is the absorbance of the sample.

\section{ABTS assay}

ABTS scavenging assay followed the method of Almeida et al., 2011, with slight modifications [10]. ABTS was dissolved in phosphate buffer ( $\mathrm{pH} 7.0,7.4 \mathrm{mM})$ and activated to ABTS.+ radical by addition of $2.6 \mathrm{mM}$ potassium persulfate in a 1:1 ratio with occasional stirring and 16-18 $\mathrm{h}$ for activation. Then, the solution was centrifuged for $5 \mathrm{~min}$ at $7000 \mathrm{~g}$; the supernatant was diluted with methanol (1:60). The experiment involves immediate reading after addition of $2850 \mu \mathrm{l}$ of ABTS to $150 \mu \mathrm{l}$ of samples at different concentrations $(9.375 \mu \mathrm{g}-$ $150 \mu \mathrm{g} / \mathrm{ml}$ ). The absorbance of color developed was read in Thermo Scientific Varioskan ELISA plate reader at $734 \mathrm{~nm}$, BHT is used as the standard. Percent ABTS scavenging $=(A C-A T) / A C * 100$, where $A C$ is the absorbance of the control and AT is the absorbance of the sample.

\section{NO scavenging}

The NO scavenging assay was done by Griess method [11]. To $100 \mu \mathrm{l}$ of the sample $(6.25 \mu \mathrm{g}-100 \mu \mathrm{g} / \mathrm{ml}), 1400 \mu \mathrm{l}$ of sodium nitroprusside solution was added and illuminated at room temperature $\left(25-30^{\circ} \mathrm{C}\right)$ for $180 \mathrm{~min}$. The reaction mixture was vortexed and $1500 \mu \mathrm{l}$ of Griess reagent was added. The absorbance of the color developed was read in Bio-Rad iMark microplate reader at $546 \mathrm{~nm}$, ascorbic acid was used as the standard. The percentage of NO scavenging was calculated as Percent NO scavenging $=(\mathrm{AC}-\mathrm{AT}) / \mathrm{AC}^{*} 100$, where $\mathrm{AC}$ is the absorbance of the control and AT is the absorbance of the sample.

\section{Ferric reducing antioxidant power (FRAP) assay}

FRAP reagent was freshly prepared by mixing $25 \mathrm{ml}$ acetate buffer, $2.5 \mathrm{ml} \mathrm{TPTZ}$ solution, $2.5 \mathrm{ml} \mathrm{FeCl}_{3}$ solution and then warmed at $37^{\circ} \mathrm{C}$ before use. In the experiment, $150 \mu$ l of $37^{\circ} \mathrm{C}$ pre-warmed FRAP reagent was mixed with $20 \mu \mathrm{l}$ of the sample of different concentrations $(6.25-100 \mu \mathrm{g} / \mathrm{ml})$ and standard $(1.25-20 \mu \mathrm{g} / \mathrm{ml})$. It was then incubated for $30 \mathrm{~min}$ at $37^{\circ} \mathrm{C}$. The absorbance was read at $593 \mathrm{~nm}$ in Shimadzu ultraviolet 1800 spectrophotometer [12]. FRAP activity is calculated as ferrous equivalence (FE), i.e., the concentration of sample which produces an absorbance value equal to that of $1 \mathrm{mM} \mathrm{FeSO}$. The absorbance of the sample was compared to the $\mathrm{FeSO}_{4}$ standard curve and the FRAP values were calculated. BHT was used as the standard.

\section{Cell culture studies on THP1 cell lines}

MTT assay

Cell viability was measured using MTT according to the kit protocol of Ezcount TM MTT cell assay. THP1 cell was seeded at a cell density of $1 \times 10^{6}$ cells/ml in RPMI-1640 w/o phenol red in a 96 well plate and incubated at $37^{\circ} \mathrm{C}$ with $5 \% \mathrm{CO}_{2}$ till they attained confluency, followed by the addition of $10 \mu \mathrm{l}$ of the samples at different concentrations $(0.001 \mu \mathrm{g} / \mathrm{ml}-10 \mu \mathrm{g} / \mathrm{ml})$ and incubated for $24 \mathrm{~h}$. MTT reagent was added and incubated in the dark at $37^{\circ} \mathrm{C}$ with $5 \% \mathrm{CO}_{2}$ for $4 \mathrm{~h}$. The culture medium was then aspirated off and solubilizing solution (DMSO) was added and mixed properly to dissolve the formazan crystals. Absorbance was read on Thermo Scientific Varioskan ELISA plate reader at $570 \mathrm{~nm}$ with a reference wavelength at $650 \mathrm{~nm}$.

\section{NO production in THP1 derived macrophage cells}

THP1 cells were seeded at a cell density of $1 \times 10^{6}$ cells $/ \mathrm{ml}$ along with PMA $\left(400 \mathrm{nM}\right.$ ) and incubated at $37^{\circ} \mathrm{C}$ with $5 \% \mathrm{CO}_{2}$ for $24 \mathrm{~h}$. Differentiated cells were treated with different concentrations of drug $(10 \mu \mathrm{g} / \mathrm{ml}, 1 \mu \mathrm{g} / \mathrm{ml}$, and $0.1 \mu \mathrm{g} / \mathrm{ml}$ ) and LPS (E. coli 0111 ) at a concentration $1 \mu \mathrm{g} / \mathrm{ml}$. It was incubated for $2 \mathrm{~h}$ at $37^{\circ} \mathrm{C}$ in $5 \% \mathrm{CO}_{2}$ in the incubator, and the supernatant was used for the analysis of NO production by THP1 derived macrophages as per the protocol of Promega kit.

\section{Statistical analysis}

All assays were done as three independent assays and the results were expressed as mean \pm standard deviation. One-way analysis of variance and the Dunnett's multiple comparison tests (GraphPad Prism ${ }^{\circledR}$ version 5.03) was used to determine the significance of test samples compared to control. $\mathrm{p}<0.05$ was considered to be statistically significant.

\section{RESULTS}

\section{Yield of fractions}

Kokilaksham kashayam was fractionated by solvent-solvent extraction method using solvents of different polarity (hexane, dichloromethane, ethyl acetate, methanol and water and were named as F1-F5, respectively). The yield of fractions was calculated by measuring the dry weight of the lyophilized samples (Table 1).

\section{Qualitative phytochemical analysis}

Phytochemicals found to be present in the different fractions are shown in Table 2.

\section{Quantitative analysis of phytochemicals}

The amount of phytochemicals (phenol, flavanoid and phenolic acid) was quantified and is shown in Table 3.

\section{Free radical scavenging assays}

The fractions were checked for the scavenging of different kind of free radicals and the efficient concentration 50 values were calculated and are shown in Table 4

\section{FRAP assay}

The FRAP assay was employed to estimate the antioxidant capacity of the fractions in vitro and BHT was used as the standard.

\section{MTT assay}

Effect of Kokilaksham kashayam fractions (F1-F5) on the viability of THP1 derived macrophages showed that the cells treated with the different concentrations $(0.001 \mu \mathrm{g} / \mathrm{ml}$ to $10 \mu \mathrm{g} / \mathrm{ml})$ are viable, as confirmed by MTT assay.

\section{NO production in THP1 derived macrophage cells}

This assay was used to determine the effect of Kokilaksham kashayam fractions on NO production in THP1 derived macrophages.

\section{DISCUSSION}

Biological system on exposure to different physiochemical and pathological states lead to the generation of numerous free radical species (reactive nitrogen species and ROS) [13] resulting in a condition called oxidative stress, where free radicals are generated beyond the body's ability to regulate their production. Oxidative stress if left uncontrolled lead to chronic inflammatory conditions such as 
cancer, neurodegenerative disorders, diabetes, and cardiovascular diseases [14]. Hence, there is a need for identifying natural compounds that are effective in controlling chronic inflammatory conditions. The therapeutic activity of herbal drugs is attributed to the presence of free radical scavengers such as phenolics, tannin, flavonoids, and flavanones [15].

Kokilaksham kashayam an ayurvedic herbal decoction prepared from H. schulli M.R. Almeida and S.M. Almeida which belongs to Acanthaceae family is widely recommended by Ayurvedic practitioners for the treatment of chronic inflammatory conditions. The present study evaluated the antioxidant activity of Kokilaksham kashayam fractions and its effects on NO production in LPS treated THP1 derived macrophage cell line, an in vitro model for chronic inflammation. The preliminary phytochemical screening of the fractions revealed the presence of alkaloids, cardiac glycoside, flavonoid, terpenoids, coumarin, and phenol. Fraction F1 due to the non-polar nature of hexane solvent in its extraction showed the presence of only steroids, saponins, and tannins when compared to other fractions whereas the presences of phytochemicals such as alkaloids, cardiac glycoside, coumarin, and phenol were found in fractions F2, F3, F4, and F5 (Table 2). Quantitative evaluation (Table 3) also showed the presence of high content of flavonoid, phenolic acids, and phenol in fractions F2, F3, and F4. Thus, the presence of phytochemicals in the Kokilaksham kashayam fractions may largely contribute to its antioxidant activities and play an important role in the beneficial effects of the herbal decoction.

Table 1: Percentage yield of fractions

\begin{tabular}{ll}
\hline Name of fractions & Yield (\%w/w) \\
\hline Hexane (F1) & 0.371 \\
Dichloromethane (F2) & 5.05 \\
Ethyl acetate (F3) & 7.64 \\
Methanol (F4) & 35.41 \\
Water (F5) & 20.76 \\
\hline
\end{tabular}

Table 2: Qualitative phytochemical analysis of fractions of Kokilaksham kashayam

\begin{tabular}{llllll}
\hline Phytochemicals & F1 & F2 & F3 & F4 & F5 \\
\hline Alkaloid & - & + & ++ & ++ & + \\
Carbohydrate & - & + & ++ & ++ & + \\
Cardiac glycoside & - & - & + & - & + \\
Flavonoid & - & + & ++ & ++ & + \\
Amino acid and proteins & - & - & - & - & - \\
Saponins & + & - & - & - & - \\
Tannins & + & + & + & ++ & + \\
Terpenoids & - & + & ++ & +++ & + \\
Quinones & - & - & - & + & + \\
Anthocyanin & - & - & - & - & - \\
Leucoanthocyanin & - & - & - & - & - \\
Coumarin & - & + & + & + & + \\
Phenol & - & + & ++ & ++ & + \\
Reducing sugar & - & + & + & ++ & + \\
Steroid & + & - & - & - & - \\
\hline A & & + & & & +
\end{tabular}

A " + " score was noted if the reagent produced only slight positive reaction,

"++" indicated for a definitive positive reaction and a "+++" was noted for

the presence of heavy reactions observed, whereas "-" indicates absence as

compared to controls which contained all reactants other than the fractions
Free radicals which are formed during normal cellular metabolism cause oxidative stress when there is an imbalanced defense mechanism by antioxidants. Flavonoids are known free radical scavengers as they exhibit several biological activities such as anti-inflammatory, antioxidant, and immunomodulatory, hence, are found to be effective scavengers of oxidizing molecules, thereby lowering formation of free radicals [16]. Hence, Kokilaksham kashayam fractions which showed the presence of a wide range of phytochemicals were analyzed for their ability to scavenge free radicals such as DPPH, ABTS, and NO. DPPH assay showed the free radical scavenging property of the fractions to evaluate its antioxidant activity [17]. Since the oxidation process produces free radicals, its formation is inhibited by antioxidants, thereby preventing the damage to the cells of living organisms. According to Bamforth et al., 1993, antioxidants with DPPH radical scavenging activity can donate hydrogen to free radicals leading to the formation of non-radical species resulting in the inhibition of propagation phase of lipid peroxidation, which can control chronic inflammatory conditions [18]. ABTS radical scavenging activity also reflects the hydrogen donating ability of fractions leading to scavenging of free radicals, thereby breaking the chain reaction caused by free radicals. High molecular weight phenolics (tannins) are reported to have more ability to quench free radicals (ABTS.+) [19]. The fractions of the herbal decoction were found to scavenge DPPH and ABTS free radicals reaffirming the antioxidant activities of the fractions (Table 4). In both assays fractions, F3 and F5 were found to be better scavengers of DPPH and ABTS radical, respectively, when compared to the standard BHT which may be due to the occurrence of active constituents that are capable of donating hydrogen to a free radical to remove odd electrons causing radical reactivity [20].

The potential antioxidant activity of fractions was quantitatively measured by FRAP assay. Since the reducing power may serve as a significant indicator of the antioxidant property, Kokilaksham kashayam fractions were checked for FRAP activity. FRAP assay showed the antioxidant potential of the different fractions, the results were compared with BHT as a positive control, and fraction F3 showed greater antioxidant capacity than all other fractions (Table 5). As the FRAP assay relies on reduction by the antioxidants, it can be concluded that this assay is a relevant tool to investigate the relationship between antioxidants and pathologies caused by oxidative stress. The results are in accordance that the phenol compound being the major constituents has a direct correlation with the antioxidant activity.

Kokilaksham kashayam fractions with its rich source of antioxidants were also found to be effectively scavenging NO. Although NO is responsible for the regulation of a number of physiological processes such as vasodilation, immune response, and neural signal transmission, its excessive accumulation results in deleterious body conditions [21]. A large amount of NO is formed during the course of inflammation, leading to increased vasodilation, tissue, and endothelial damage. Hence, the proinflammatory role of NO needs to be regulated as its elevated level causes a chronic inflammatory condition such as rheumatoid arthritis. The NO scavenging assay shows a close relationship between the phenolic content and antioxidant property, as the NO scavenging property of all the fractions was found to be better than the standard ascorbic acid. Excessive production of NO from inducible nitric oxide synthase (iNOS) is reported in chronic inflammatory conditions [22]. As per different studies, flavonoids are found to be capable of regulating iNOS, by inhibiting the production of NO so as to counter the course of chronic inflammation. The NO assay done in THP1 derived macrophages revealed that all fractions inhibited the NO production in

Table 3: Quantitative determination of total phenol, flavonoid, and phenolic acid

\begin{tabular}{llll}
\hline Fraction & Total phenol (mg GAE/g) & Flavonoid (mg QUE/g) & Phenolic acid (mg CAE/g) \\
\hline F2 & $32.833 \pm 1.258$ & $13.455 \pm 0.315$ & $38.3 \pm 7.638$ \\
F3 & $50.667 \pm 2.363$ & $14.848 \pm 0.735$ & $273.3 \pm 31.853$ \\
F4 & $24.833 \pm 1.528$ & $10.061 \pm 1.528$ & $68.3 \pm 7.217$ \\
F5 & $20.667 \pm 2.082$ & $9.758 \pm 1.290$ & $40.3 \pm 4.330$ \\
\hline
\end{tabular}

All values are expressed as mean \pm SD of three independent experiments. SD: Standard deviation 
Table 4: $\mathrm{EC}_{50}$ values of Kokilaksham kashayam fractions and standard for different free-radical scavenging experiments

\begin{tabular}{llll}
\hline Sample & $\begin{array}{l}\text { DPPH assay } \\
\text { EC50 }(\mu \mathrm{g} / \mu \mathrm{l}) \\
\mathbf{\pm S D}\end{array}$ & $\begin{array}{l}\text { ABTS assay } \\
\mathbf{E C 5 0}(\mu \mathrm{g} / \mu \mathrm{l}) \\
\mathbf{\pm S D}\end{array}$ & $\begin{array}{l}\text { NO assay } \\
\mathbf{E C 5 0}(\boldsymbol{\mu g} / \mu \mathrm{l}) \\
\mathbf{\pm S D}\end{array}$ \\
\hline F1 & $73.91 \pm 0.18$ & & \\
F2 & $0.319 \pm 0.019$ & $0.915 \pm 0.022$ & $2.46 \pm 0.065^{*}$ \\
F3 & $0.299 \pm 0.028^{*}$ & $1.15 \pm 0.027$ & $2.351 \pm 0.126^{*}$ \\
F4 & $0.551 \pm 0.045$ & $1.001 \pm 0.008$ & $0.72 \pm 0.138^{*}$ \\
F5 & $1.146 \pm 0.038$ & $0.827 \pm 0.02^{*}$ & $4.001 \pm 0.002^{*}$ \\
BHT & $2.27 \pm 0.13$ & $0.856 \pm 0.02$ & - \\
Ascorbic acid & - & - & $5.21 \pm 0.24$ \\
\hline
\end{tabular}

All values are expressed as mean \pm SD of three independent experiments. $\mathrm{EC}_{50}$ value for Kokilaksham kashayam fractions as compared to positive control. ${ }^{*} \mathrm{p}<0.05$, significant as compared to the positive control. SD: Standard deviation, DPPH: 2,2-diphenyl-1-picrylhydrazyl, ABTS: 2,2'-azino-bis (3-ethylbenzothiazoline-6-sulfonic acid, BHT: Dibutylhydroxytoluene, $\mathrm{EC}_{50}$ : Efficient concentration 50

Table 5: The effect of Kokilaksham kashayam fractions on ferric reducing antioxidant potential

\begin{tabular}{ll}
\hline Sample & Concentration corresponding to $\mathbf{F E}(\mathbf{m g} / \mathbf{m l})$ \\
\hline F1 & $778.55 \pm 0.495$ \\
F2 & $84.615 \pm 0.063$ \\
F3 & $12.882 \pm 0.126$ \\
F4 & $37.109 \pm 0.138$ \\
F5 & $278.538 \pm 0.02$ \\
BHT & $6.75 \pm 0.0019$ \\
\hline
\end{tabular}

The FE of the fractions is expressed as mean \pm SD of three independent experiments. SD: Standard deviation, BHT: Dibutylhydroxytoluene, FE: Ferrous equivalence

Table 6: The effect of Kokilaksham kashayam fractions on the production of nitric oxide in THP1 derived macrophages was compared with indomethacin, the positive control

\begin{tabular}{ll}
\hline Sample & IC $_{\mathbf{5 0}} \mathbf{\pm S E}(\boldsymbol{\mu g} / \mathbf{m l})$ \\
\hline F1 & $31.49 \pm 0.214$ \\
F2 & $4.873 \pm 0.064^{*}$ \\
F3 & $11.27 \pm 0.126$ \\
F4 & $12.3 \pm 0.062$ \\
F5 & $793.7 \pm 0.297$ \\
Indomethacin & $6.594 \pm 0.13$ \\
\hline
\end{tabular}

Results are expressed as mean \pm SE of three independent experiments. The $\mathrm{IC}_{50}$ value for Kokilaksham kashayam fractions as compared to the positive control. ${ }^{*} \mathrm{p}<0.05$, significant as compared to the positive control. $\mathrm{IC}_{50}$ : Half maximal inhibitory concentration, SE: Standard error

LPS stimulated system and the half maximal inhibitory concentration of fraction F2 was found to be much better than the positive control Indomethacin (Table 6). This, in turn, suggests that the fractions could regulate NO production in the in vitro model of chronic inflammatory conditions, thereby controlling oxidative stress state. These results show that the fractions of the herbal decoction may be a promising source of natural antioxidants which could be further studied. Studies by Deepa et al. showed that due to the presence of antioxidants in plant and plant-derived products, they are highly efficient in reducing the damaging effect of ROS [23]. Thus, the observations help in evaluating the antioxidant ability of Kokilaksham kashayam and can be considered as a preliminary step toward the scientific validation of the herbal decoction.

\section{CONCLUSION}

Data presented in this study indicate that Kokilaksham kashayam fractions have a good antioxidant property which could be attributed to the presence of flavonoids, terpenoids, alkaloids, tannins, saponins, glycosides, and phenolic compounds in it. Further, these fractions could effectively inhibit different free radicals and thereby can be considered as effective managers of free radical-mediated chronic inflammatory diseases as shown in LPS stimulated THP1 derived macrophage cell culture system. Further work is being carried out for the isolation and identification of the antioxidative components present in it.

\section{ACKNOWLEDGMENT}

This work was carried out with the support from Kerala State Council for Science Technology and Environment (KSCSTE Order No.235/ WSD-BLP/KSCSTE/2016-17). The authors are grateful to DBT- MSUBIPLSARE (BUILDER) programme (BT/PR4800/INF/22/152/2012 dated 22/03/2012), School of Biosciences, Mahatma Gandhi University, Kerala, for providing instrument facilities. The authors would like to thank Arya Vaidya Sala Kottakkal, Kerala, for their support.

\section{AUTHORS' CONTRIBUTIONS}

The first author carried out the experiments as per the instructions and guidance of the corresponding author.

\section{CONFLICTS OF INTEREST}

Authors declare that they have no conflicts of interest.

\section{REFERENCES}

1. Ahmed AU. An overview of inflammation: Mechanism and consequences. Front Biol China 2011;6:274-81.

2. Chang CL, Lin CS, Lai GH. Phytochemical characteristics, free radical scavenging activities, and neuroprotection of five medicinal plant extracts. Evid Based Complement Altern Med 2012;2012:1-8

3. Betteridge DJ. What is oxidative stress? Metabolism 2000;49:3-8.

4. Rajesh KD, Vasantha S, Rajesh NV, Panneerselvam A. Qualitative and quantitative phytochemical analysis in four pteridophytes. Int J Pharm Sci Rev Res 2014;27:408-12

5. Kumar DN, Nair AS, Murali M, Devi PS. Qualitative phytochemical analysis of triphala extracts. J Pharmacogn Phytochem 2017;6:248-51.

6. Chua LS, Latiff NA, Lee SY, Lee CT, Sarmidi MR, Aziz RA. Flavonoids and phenolic acids from Labisia pumila (Kacip Fatimah). Food Chem 2011;127:1186-92.

7. Kumar S, Kumar D, Manjusha, Saroha K, Singh N, Vashishta B, et al. Antioxidant and free radical scavenging potential of Citrullus colocynthis (L.) schrad. Methanolic fruit extract. Acta Pharm 2008;58:215-20.

8. Chinchu JU, Kumar BP. In vitro anti-lipase and antioxidant activity of polyherbal ayurvedic medicine varanadi kashayam. Int J Pharm Sci Res 2018;9:5373-81.

9. Floegel A, Kim DO, Chung SJ, Koo SI, Chun OK. Comparison of ABTS/DPPH assays to measure antioxidant capacity in popular antioxidant-rich US foods. J Food Compost Anal 2011;24:1043-8.

10. Almeida MM, de Sousa PH, Arriaga ÂM, do Prado GM, de Magalhães CE, Maia GA, et al. Bioactive compounds and antioxidant activity of fresh exotic fruits from Northeastern Brazil. Food Res Int 2011;44:2155-9.

11. Jagetia GC, Baliga MS. The evaluation of nitric oxide scavenging activity of certain Indian medicinal plants in vitro: A preliminary study. J Med Food 2004; 7:343-8.

12. Lu Y, Khoo TJ, Wiart C. Antioxidant activity determination of citronellal and crude extracts of Cymbopogon citratus by 3 different methods. Pharmacol Pharm 2014;5:395-400.

13. Bose S, Kim H. Evaluation of in vitro anti-inflammatory activities and protective effect of fermented preparations of rhizoma Atractylodis macrocephalae on intestinal barrier function against lipopolysaccharide insult. Evid Based Complement Alternat Med 2013;2013:363076.

14. Lidon F, Silva M. An overview on applications and side effects of antioxidant food additives. Emirates J Food Agric 2016;28:823-32.

15. Priyanga KS, Vijayalakshmi K. Investigation of antioxidant potential of quercetin and hesperidin: An in vitro approach. Asian J Pharm Clin Res 2017;10:83-6

16. Mahmoud AM, Hernández Bautista RJ, Sandhu MA, Hussein OE. Beneficial effects of citrus flavonoids on cardiovascular and metabolic health. Oxid Med Cell Longev 2019;2019:5484138.

17. Da Porto C, Calligaris S, Celotti E, Nicoli MC. Antiradical properties of 
commercial cognacs assessed by the DPPH(.) test. J Agric Food Chem 2000;48:4241-5.

18. Bamforth CW, Muller RE, Walker MD. Oxygen and oxygen radicals in malting and brewing: A review. J Am Soc Brewing Chem 1993;51:79-88.

19. Hagerman AE, Riedl KM, Jones GA, Sovik KN, Ritchard NT, Hartzfeld PW, et al. High Molecular Weight Plant Polyphenolics (Tannins) as Biological Antioxidants. J Agric Food Chem 1998;46:1887-92.

20. Gangwar M, Gautam MK, Sharma AK, Tripathi YB, Goel RK, Nath G, et al. Antioxidant capacity and radical scavenging effect of polyphenol rich Mallotus philippenensis fruit extract on human erythrocytes: An in vitro study. ScientificWorldJournal 2014;2014:279451.

21. Mapunda P, Mligo C, Cosmas L, Herbert VM. Evaluation of free radical scavenging ability and antiradical activities of Ximenia caffra fruit extracts at different ripening stages. Int J Pharm Pharm Sci 2019; 11:55-60.

22. Kröncke KD, Fehsel K, Kolb-Bachofen V. Inducible nitric oxide synthase in human diseases. Clin Exp Immunol 1998;113:147-56.

23. Deepa M, Darsan MB, Ramalingam C. In vitro evaluation of the antioxidant, anti inflammatory and antiproliferative activities of the leaf extracts of Excoecaria agallocha L. Int J Pharm Pharm Sci 2015;7:346-52. 